\title{
Toroidal Microinstability Studies of High Temperature Tokamaks
}

G. Rewoldt and W. M. Tang

Princeton Plasma Physics Laboratory, Princeton Liviversity.

Princeton, View Jersey 085 3

\section{ABSTRACT}

Results from comprehensive kinetic microinstability calculations $:$ :' presented showing the effects of torojdicity on the ion temperature gradient mrite and its relationship to the trapped-electron mode in high-temperature tokamak plasmas. The corresponding particle and energy fluxes have also been computed. It is found that, although drift-type microinstabilities persist over a wide range of : lues of the ion temperature gradient parameter $\eta_{i} \equiv\left(d \ln T_{i} / d r\right) /\left(d \ln n_{i} / d r\right)$, the :aracteristic leatures of the dominant mode are those of the $\eta_{i}$-type instabilit: rhen $\eta_{i}>\eta_{i c} \sim 1.2$ to 1.4 and of the trapped-electron mode when $\eta_{i}<\eta_{i c}$.

\section{DISCLAIMER}

\begin{abstract}
This repon was prepured as an account of work sporisoted by an agency of the United Siates Government. Netther the United States Government nor any agency thereor, for any of their employees. makes any warranty, express or amplied, or assumes any legal liablity or responsibility for the accuracy. completeness, or usefulness of any information, apparatus, product, or process disclosed, or represents that its use would not infringe privately owned rights. Reference herein to any specific commercial product, process. or service by trade name, lrademark, manufacturet. of otherwise dees nal necessibrily constivute or imply tis endorsement, recommendation, or fatoring by the Linited States Guvernment or any atgency thereof The views and opinions of athors expressed herein do not necessarily slate or reflect thuse of the Uniled Slates Government or any agency thereof.
\end{abstract}




\section{INTRODUCTION}

There have been a number of papers recently concerned with tne icn temperature gradient $\left(\eta_{z}\right)$ mode in the linear and nonlinear regimes. ${ }^{1-i}$ Here. $\eta_{j} \equiv\left(d \ln T_{j} / d r\right) /\left(d \ln n_{s} / d r\right)$. However. much of this work simplifies the geometry to that of an unsheared or sheared slab. or approximates the electron response as adiabatic, or employs purely fluid equations. Any of these approximations removes the effect of the trapped electrons in toroidal geometry. In the present work. the goals are to show the effect of toroidicity on the usual $\eta_{1}$ mode, and to show the relationship between the $\eta_{i}$ mode and the usual trapped-electron mode. Toroidal effects enter in a number of different ways. In addition to the trapped-electron effects. the toroidal curvature causes jon and electron magnetic drifts, which can make both resonant and nonresonant contributions to the eigenfrequency. This effect has been studied before in Ref. 8 in an approximate calculation. Also, the ballooning of the eigenfunction to the weak magnetic field side of the tokamak is a consequence of the greater unfavorable curvature effects as well as of the increased number of trapped particles in this region.

In the very simplest aralytic calculation of the $\eta_{i}$-mode eigenfrequency $\omega$ in unsheared slab geometry, it is assumed that $k_{\|} v_{i} \ll \omega \ll k_{\|} v_{e}$, where $k_{\|}$is the wave number along the magnetic field line and $v_{j} \equiv\left(2 T_{3} / m_{j}\right)^{1 / 2}$. Taking $\eta_{i} \gg 1$ and $k_{\perp} \rho_{i} \ll 1$, where $k_{\perp}$ is the wave number perpendicular to the magnetic field line and $\rho_{i}$ is the average ion gyroradius. and assuming the electron response to be adiabatic, the quasineutrality condition implies that $\omega^{3} \simeq-k_{i l}^{2} v_{1}^{2}\left(T_{e} / 2 T_{i}\right) w_{w 1} \eta_{i}$, where $\omega_{=1}$ is the ion diamagnetic drift frequency. The unstable root is the $\eta_{1}$ mode while the marginally stable root becomes the electron drift mode, so that the two coots are distinct. However, in toroidal geometry, where $k_{\|}{ }^{y}$, is replaced by $\bar{F}_{1}$, the average transit frequency for untrapped particles of species $j$, it will be shown that. in realistic cases, the mode frequency can be such that $|w| \leq \overline{w i t}_{\text {, }} \ll \bar{\nu}_{\mathrm{i} e}$. This implies that the untrapped ion transit frequency resonances (ion Landau damping) will be strong, but it also implies that an expansion in $|\cdot| l \mid=i n \ll l$, yielding a distinct ion sound term. is no longer possible. Thus, the mode equation remains transcendental and the number of roots is 
indefinite. This suggests the possibility that the electron drift mode root and the ion sound $\left(\eta_{1}\right)$ mode root may be combined together into a single. hybrid root. It will be shown in the results here that this can be the case.

A relatively complete computational model for tokamai linear eigenmodes and their associated quasilinear transport is emplosed here. The equations solved and the solution methods have previously been presented in great detail in Refs. 9-11. This material will not be repeated here because the motivation behind the present paper is the application of swh procedures to address the important transport question regarding the relationship between the $\eta_{1}$-type mode and the trapped-electron instability: The calculation is essentially an exact solution of the linearized gyrokinetic equation for large $n$ (toroidal mode number). employng the ballooning formalism. It ailows for arbitrary ratios between the mode frequency. -2 , the transit frequency for untrapped particles, $\omega_{t}$, the bounce frequency for trapped particles. $\omega^{\prime}$, and the magnetic (gradient and curvature) drift frequency, $\omega_{d}$. Trapped and untrapped particles for every species are included. and full finite Larmor radius effects are retained. The model collision operator emploved should be relatively accurate in the banana regime and the lower end of the plateau regime, as described in Ref. 10. Input data for the calculation, such as radial density and temperature profiles, are taken from results of BALDLF transport $\operatorname{code}^{12}$ runs. The corresponding pressure and safety factor profiles are used in calculiting the numerical MHD equilibria employed in the instability calculation. For illustrative purpors. a!l instability results presented here are calculated in the electrostatic limit. As pointed out in Refs. 9 and 11 , inclusion of finite- 3 modifications in these computations is quite straight forward.

The most directly relevant previsus calculation is that in Ref. 1 , where the effects of an approximate trapped-electron time-avrage term on an ion temperature gradient mode are considered. However, this calculation makes several significant approximations. In particular. all bounce and transit frequency effects are omit ted. so that the jon temperature gradient mode considered is not the one mentioned earlier coming from the ion sound term. Instead. 
it is a related instability coming mainly from the toroidal ion magnetic drift frequencs, in combination with $\eta_{\text {. }}$. As will be shown. for realistic parameters, the relevant instabilities an be in a regine where $\omega_{!} ! \bar{j}_{1}$. so that finite ion transit frequency effects are critical. Also. Ref. 1 neglects the sariation of the eigenfunction along the magnetic field line. which is needed for quantitative accuracy. Cerertheless. the results here have some qualitative features in common with those of Ref. 1.

Simerical results are presented in Sec. II, and conclusions are presented in Sec. III.

\section{Numerical Results}

Results will first be presented for a case ${ }^{13}$ corresponding to a (now superceded) design for the Compact Ignition Tokamak (C.IT), with vacuum najor radius $R_{0}=1.15$ m. toroidal magnetic field $B_{0}=10 \mathrm{~T}$. and plasma current $I_{p}=9 \mathrm{MA}$. This is the same case employed in Ref. 1t, but now without any o-particles or helium ash particles, and with the eigenmode calculation performed in the electrostatic limit. Also, the numerical MHD equilihrium is recomputed for decreased equilibrium pressure, but with the same profile shape. The local parameters on the chosen magnetic surface with average minor radius $r \simeq 1 / 2$ are $3=0.166 \%, q=1.17 . \hat{s} \equiv r(d q / d r) / q=0.456 . \epsilon_{0} \equiv r / R_{0}=0.154, R_{0}=180 \mathrm{~cm} . \nu_{q}^{*} \equiv$ effective electron collision frequency/average trapped electron bounce frequency $=0.0035$. $n_{e}=n_{i}=3.71 \times 10^{14} \mathrm{~cm}^{-3}, m_{i}=2.5 \mathrm{amu}, T_{e}=18.9 \mathrm{keV}, T_{i}=19.4 \mathrm{keV}, n=58$, and $k_{y} \rho_{i}=0.400$. Results will be presented as $\eta_{i}$ and $\eta_{e}$ are varied from their BALDLR values; $\eta_{1}=1.3 t$ and $\eta_{e}=1.28$. For this case. as $\eta_{i}$ is varied, $\eta_{e}$ varies in proportion, so that always $\eta_{s} / \eta_{\mathrm{s}}=0.955$. Also, as $\eta_{\mathrm{i}}$ varies. the total pressure gradient is kep: fixed. This means. for instance, that as $\eta_{1}$ increases. so that $d T_{1} / d r$ and $d T_{t} / d r$ increase, $d n_{1} / d r=d n_{e} / d r$ decreases so as to maintain a fixed total pressure gradient. In this way. the parameters remain consistent with the MHD equjlibrium. which results from a specific pressuce gradient on the chosen magnetic surface. 
Results for the growth rate, $\%$ and the real frequency $\nu_{r}$. in units of the electron diamagnetic drift frequency, - -.e. are shown in Fig. 1 for this case as $\eta_{\text {, }}$ and $\eta_{e}$ are varied. It can be seen from the growth rate curve in Fig. la for the actual collisionality ralue. $w^{*}=0.0035$. that the instability has two regimes: for $\eta_{1} \geq 1,4$, the growth rate increases monotonically, and almost linearly: with $\eta_{i}$. In this regime, the fluid $\eta_{i}$-mechanism, which is responsible for destabilizing the $\eta_{1}$ mode in the simple slab geometry limit mentioned earlier. destabilizes this toroidal mode. However. as $\eta_{i}$ decreases from 1.t. the growth rate increases again sighty. before falling to zero for $\eta_{2} \simeq-0.4$. In this regime. the trapped-electron timeaverage magnetic drift (precession)" frequency resonance mechanism is dominant. It is this mechanism which is responsible for the usual collisionless trapped-electron mode. In this case. a single root of the mode equation combines the usual collisionless trapped-electron mode and the usual $\eta_{i}$ mode, and will be referred to as the trapped-electron- $\eta_{i}$ mode.

The effects of the trapped electrons can be greatly reduced by increasing the collisionality. since the trapped-electron time-average term varies as $1 / \nu_{*}^{*}$ for $\nu_{e}^{*}$ sufficiently large. If $v^{*}$ is artificially increased to 1.0 by increasing $n_{e}=n_{1}$ to $1.23 \times 10^{17} \mathrm{~cm}^{-3}$, the results in Fig. la show that the regime destabilized by the trapped-electron magnetic drift resonance mechanism is eliminated, and the mode is damped for $\eta_{i} \leqslant 1.1$. The corresponding real frequencies, shown in Fig. $1 b$, start out in the electron diamagnetic direction at small $\eta_{z}$ and make a transition to the ion diamagnetic direction as $\eta_{\mathrm{t}}$ increases past 1.1 .

The dependence of $y$ and $\omega_{\tau}$ on $k_{\theta} \rho_{i} \propto n$ for the mode is shown in Fig. 2 for the nominal BALDL'R values of $\eta_{i}=1.34$ and $\eta_{e}=1.28$. The value $k_{\theta} \rho_{i}=0.400$ chosen for Fig. 1 is seen to be close to the maximum of $\gamma$ for both collisionalities. Increasing $k_{\theta} \rho_{i}$ is also seen to push the real frequency in the ion diamagnetic direction.

The results shown in Fig. 1 correspond to a single root resulting from the coupling of the collisionless trapped electron mode and the $\eta_{1}$ mode, with an eigenfunction that is essentially a simple gaussian along the magnetic field line, well localized around the magnetic field minimum. Cormally, this is the most unstable root. There are other roots as well. some 
with lower growth rates. and some that are damped. In fact, since the eigenvalue equation is transcendental in character, there are an indeterminate number of possible roots.

The other case to be considered here corresponds to a chosen time in a BADLR transport code run ${ }^{25}$ modeling a "supershot" (shot 2014) in the Tolamak Fusion Tes: Reactor ${ }^{\text {ti }}$ (TFTR) with $R_{0}=2.55 \mathrm{~m} . B_{0}=4.5 \mathrm{~T}$. and $I_{p}=0.8 \mathrm{MA}$. To make the calculation more realistic, a beam species $(b)$ from neutral beam injection heating is included in the calculation. along with the background deuterium ions (i) and the electrons ( $e$ ). The equilibrium distribution function $F_{b}(E,(y / l)$ for the beam species as calculated by the BILDTR code for this case with balanced co- and counter parallel neutral beam injertion is shown in Fig. 3. Here. $E$ is the particle energy and $v / v$ is a dimensionless pitch-angle variable. with $x$ being the particle velocity component along the magnetic field, evaluated when the particle is at the magnetic field minimum. The results for the trapped-electron- $\eta_{1}$ mode for this strongly non-Maxwellian distribution will be compared with those for a Maxwellian distribution with the same number density and the same average energy, and to results with no beam species. In this last case, the density and density gradient of the background ions are adjusted to maintain the condition of bulk neutrality and its radial derivative. The local parameters on the chosen magnetic surface with $r / a \simeq 1 / 2$ are $\beta=1.66 \% . q=1.15, \dot{s}=0.456 . \epsilon_{0}=0.068$. $\nu_{e}^{*}=0 . n_{e}=5.54 \times 10^{13} \mathrm{~cm}^{-3} . n_{1} / n_{e}=0.901, n_{b} / n_{e}=0.099, T_{1}=12.8 \mathrm{keV}, T_{b}=32.9$ keV for the Maxwellian distribution, $T_{e}=4.68 \mathrm{keV}, \eta_{k}=2.65$ for the Maxwellian distribution. $\eta_{e}=1.15 . r_{n t} / r_{n e}=0.914$. and $r_{n b} / r_{n e}=6.58$, where $r_{n}, \equiv-(d \ln n, / d r)^{-1}$. The MHD equjlibrium is catculated numerically with a fixed. circular boundary. The instability calculation is again performed in the electrostatic limit. for $n=13$ or $k_{9} \rho_{i}=0.356$.

Results for the trapped-electron- $\eta$, node growth rate. $\gamma$, and real frequency, wr. are shown in Fig. 4. In this case. $\eta_{t}$ and $\eta_{b}$ and the total pressure gradient are kept fixed as $\eta_{2}$ is varied. Looking first at the growth rate curve for the case with so beam species. it can be seen that, for $\eta_{\mathrm{z}}>1$.2. the growth rate increases monotonically and almost linearly with $\eta_{1}$. Again. this is the regime where the $\eta_{1}$-mechanism is dominant. For $\eta_{1}$ decreasing 
from 1.2. the growth rate increases again, peaking around $\eta_{3}=0$, and falls to zero only for $\eta_{i} \simeq-0 . \bar{T}$. Again. this is the regime dominated $b_{y}$ the trapped-electron timie-average magnetic drift (precession) frequency resonance mechanism. Addition of the beam species with the Maxwcilian distribution increases the growth rate moderately for all $\eta_{1}>0$. With the non-Maxwellian distribution. the increase is almost doubled. but is still moderate. The corresponding real frequencies are shown in Fig. lb. Again. there is a transition from the electron diamagnetic direction to the ion diamagnetic direction as $\eta_{1}$ increases. The presence of the heam species has very little effect on the real frequency. Sote that. over the entire range of $\eta_{1} .|-\dot{i}| \leq \bar{m}_{b_{1}}$. the average trapped-ion bounce frequency. The common approximation, that $!_{i} \mid \rightarrow$ is clearly invalid in this realistic case.

The perturbed electrostatic potential eigenfunctions. $\Phi(\theta)$, where $\theta$ is the extended poloidal angle in the ballonning representation (ballooning coordinate along the field line). are shown in Fig. 5 wr the cases with no beam species for $\eta_{i}=0$ and $\eta_{i}=3$. For $\eta_{i}=0$. the eigenfunction is well localized around $\theta=0$, the magnetic field minimum. where the trapped electrons are localized and where there is "bad" magnetic curvature. For $\eta_{1}=3$. the mode is still weil localized, but the width is somewhat greater. This is allowed because the $\eta_{1}$-mechanism is not dependent on trapped particles or magnetic drifts, so the most unstable eigenfunction spreads out somewhat to decrease the stabilizing effects of the ion transit frequency resonances (ion Landau damping) and of the parallel energy convection ithat corresponds to the ion sound term in the case of large $|\omega| / \bar{w}_{t i} \mid$.

The dependence of the growth rate and real frequency on $k_{\theta} \rho_{i} \propto n$ is shown in Fig. 6 for this case with no beam species and with the non-Maxwellian beam species, for $\eta_{i}=0.51$ or 0.56 and for $\eta_{1}=2$. In this case. the growth rate peatis for $k_{\theta} \rho_{1} \simeq 0.6$ when $\eta_{i}=2$ and for $k_{5} \rho_{\mathrm{s}} \simeq 1.0$ when $\eta_{\mathrm{s}}=0.51$ or 0.56 . This difference is as expected, since finite Larmor radius

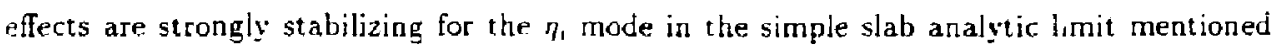
earifer. whereas the collisionless trapped-electron mode growth rate typically peats for $k_{z} p_{\mathrm{a}}$ 
of order unity. Again. the real frequency is pushed in the ion diamagnetic direction by increasing $k_{j} p$ :

The quasilinear fluxes of tons and electrons. $\Gamma$. of electron energy. $Q$. and of ion $\mathrm{m}$ 'rgy: $Q$. can be calculated as rescribed in Refs. 10 and 11 . Here. $Q$, is the lolal energy flux. including the convective part. A purely quasilinear calculation does not determine the saturation level of the instability. aad hence the absolute level of anomalous transport. but it does specifically determine the ratius of fluxes. e.g.. $T_{1} \Gamma / Q_{\text {, and }} Q_{e} / Q_{1}$. These ratios arr shown for this TFTR case with no beam species in Fig. $T$. For $\eta_{1}<1, T_{1} \Gamma \sim Q_{0} \sim Q_{1}$, while for $\eta_{t}>1, Q_{1} \gg T_{1} \Gamma \sim Q$. This hifference is understandable in terms of the two instability mechanisms involved. If there were no electron dissipation in the eigenmode equation. (i.t.. if the electron response were purely adiabatic with perturbed electron distribution function $\left.\tilde{f}_{c}=\left(\epsilon \dot{\Phi} / T_{e}\right) F_{\text {me }}\right)$, then the perturbed electrostatic potential $\dot{\Phi}$, the perturbed electron den. sity $\tilde{n}_{e}=\left(\epsilon \tilde{\Phi} / T_{e}\right) n_{e}$, the perturbed ion density $\tilde{n}_{i}\left(=\tilde{n}_{e}\right.$ by the quasineutrality condition). and the perturbed electron pressure $\dot{p}_{e}=\left(e \tilde{\Phi} / T_{e}\right) n_{e} T_{e}$ would all be exactly in phase. Then $\Gamma=\Gamma_{1}=\Gamma_{e} \times\left(\dot{l}_{E}, \tilde{n}_{e}\right) \times \operatorname{Im}\left(\tilde{\Phi}^{*} \tilde{n}_{-}\right)$and $Q_{e} \times\left\langle\bar{e}_{E r} \tilde{p}_{e}\right) \propto \operatorname{Im}\left(\tilde{\Phi}^{\cdot} \tilde{p}_{e}\right)$ would be identically zero. Here, $\bar{v}_{E r}$ is the radial component of the perturbed $\boldsymbol{E} \times \boldsymbol{B}$ drift velocity. However. the perturbed ion pressure $\bar{p}_{1}$ can be out of phase with the perturbed electrostatic potential, since $\tilde{p}_{i} \neq \tilde{p}_{e}$. so $Q_{i} \times\left\langle\hat{i}_{E r} \dot{p}_{i}\right\rangle \times \operatorname{Im}\left(\bar{\Phi}^{\prime} \bar{p}_{1}\right)$ can be nonzero, due to the destabilization from the $\eta_{\mathrm{i}}$-mechanism. If some small anount of electron dissipation were then added, mainly from the trapped-electron magnetic drift frequency resonance in the present instance. a correspondingly small amount of particle flux and electron energy flux would result. The jon energy flux, however. coming from the $\eta_{1}$-mechanism. would be rach larger. This is the situation when $\eta_{1}>1$. For $\eta_{i}<1$. On the other hand. the trapped-electron magnetic drift frequency resonance mechanism is dominant. Since it gives nonzero contributions to all three luxes, it is not surprising that they would be roughly comparable. 


\section{CONCLUSIONS}

In both of the realistic cases presented here, the usual $\eta_{\text {i }}$ mode was seen to connect to the usual collisionless trapped-electron mode as $\eta_{2}$ decreased. In an academic sense. this eifecturely removes the threshold value of $\eta_{1}$ for instability, as noted previously in Ref. 1 . However. in a more realistic sense. the physics does indeed change around the threshold. $\eta_{i c}$. Specifically, the dominant destabilization mechanism and the dominant form of anomalnus transport do change at $\eta_{i c} \simeq 1.2$ to 1.4 . For $\eta_{i}>\eta_{i c}$, the usual fluid $\eta_{i}$-mechanism for instability is dominant and the quasilinear ion energy flux greatly exceeds the electron energy fus or the particle flux. On the other hand, for $\eta_{i}<\eta_{i c}$, the trapped-electron time-average magnetic drift (precession) frequency resonance mechanism for instability is dominant, and all three fluxes are comparable. In future work. it will be of considerable interest to compare the results of this type of linear and quasilinear microinstability study with corresponding experimental results in high-temperature tokamaks.

\section{ACKNOWLEDGMENTS}

The authors would like to thank D. P. Stotler, G. Bateman, and M. H. Redi for providing the BALDLR transport code results. This work was supported by United States Department of Energy Contract No. DE-AC02-76-CHO-3073. 


\section{REFERENCES}

${ }^{1}$ F.. Romanelli and S. Briguglio. "Toroidal semicollisional microinstabilities and anomalous electron and ion transport," Report JET-P(S8)31. submitted to Phys. Fluids.

${ }^{2}$ F. Romanelli, Phys. Fluids B i, 1018 (1989).

${ }^{3}$ H. Biglari, P. H. Diamond, and M. X. Rosenbluth, Phys. Fluids B 1, 109 (1989).

${ }^{4}$ W. W. Lee and W. M. Tang, Phys. Fluids 31, 612 (1988).

${ }^{5}$ R. E. Waltz. Phys. Fluids 31. 1962 (1988).

${ }^{6}$ R. Dominguez and R. E. Waltz. Phys. Flujds 31, 3147 (1988).

'T. S. Hahm and W. M. Tang, Phys. Fluids B 1, 1185 (1989).

${ }^{3}$ C. Z. Cheng and K. T. Tsang, Fhys. Fluids 21, $6 \pm 3$ (1981).

${ }^{9}$ G. Rewoldt, W. M. Tang, and M. S. Chance, Phys. Fluids 25, 480 (1982).

${ }^{10}$ W. M. Tang, G. Rewoldt, and Liu Chen, Phys. Fluids 29, 3715 (1986).

${ }^{11}$ G. Rewoldt, W. M. Tang, and R. J. Hastie, Phys. Fluids 30, 807 (1987).

${ }^{12}$ C. E. Singer, D. E. Post, D. R. Mikkelsen, M. H. Redi, A. Mckenney, A. Silverman, F. G. P. Seidl, P. H. Rutherford, R. J. Hawryluk, W. D. Langer, L. Foote, D. B. Heifetz, W. A. Houlberg, M. H. Hughes, R. V. Jensen, G. Lister, and J. Ogden, Comp. Phys. Comm. 49, 275 (1988).

${ }^{13}$ See National Technical Information Service Document No. PPPL-2510, by D. P. Stotler and G. Bateman (Princeton Plasma Physics Laboratory Report PPPL-2510, 1988). Copies may be ordered from the National Technical Information Service, Springfield. Virginia 22161. The price is $\$ 7.00$ plus a $\$ 3.00$ handling fee. All orders must be prepaid. ${ }^{14}$ G. Rewoldt. Phys. Fluids 31, 3727 (1988).

${ }^{15}$ M. H. Redi (private communication).

${ }^{16}$ R. J. Hawryluk, V. Arunasalam. M. G. Bell, M. Bitter, W. R. Blanchard, ‥ L. Bretz. R. Budny, C. E. Bush, J. D. Callen, S. A. Cohen, S. K. Comts, S. L. Davis, D. L. Dimock. H. F. Dylla, P. C. Efthimion, L. C. Emerson, A. C. England, H. P. Eubank, R. j. Fonck, E. Fredrickson, H. P. Furth, G. Gammel, R. J. Goldston, B. Grek, L. R. Grisham, G. 
Hammett. W. W. Heidbrink. H. W. Hendel, h. W. Hill. E. Hinnov, S. Hiroe. H. Hsuan. R. A. Huise. h. P. Jaehnig. D. Jassby. F. C. Jobes, D. W. Johnson. L. C. Johnson. R. Kaita. R. Kamperschroer, S. M. Kaye, S. J. Kilpatrick. R. J. Knize, H. Kugel, P. H. LaMarche, B. LeBlanc. R. Little, C. H. Ma. D. M. Manos. D. K. Mansfield. R. T. McCann. M. P. McCarthy, D. C. McCune, K. McGuire, D. H. Mc Veill. D. M. Meade. S. S. Medley, D. R. Miktielsen, S. L. Milora. W. Morris, D. Mueller. V. Mukhovatov. E. B. Veischmidt, J. O'Rourke, D. K. Owens. H. Park. N. Pomphrey, B. Prichard. A. T. Ramsey, M. H. Redi. A. L. Roquemore. P. H. Rutherford, X. R. Sauthoff, G. Sohilling. J. Schivell, G. L. Schmidt, S. D. Scott, S. Sesnic. J. C. Sinnis. F. I. Stauffer. B. C. Stratton, G. D. Tait. G. Taylor, J. R. Timberlake, H. H. Towner, M. Llrickson, $\checkmark$. Vershkov, S. von Goeler, F. Wagner. R. Weiland, J. B. Wilgen. W. Willams, K. L. Wong, S. Yoshikawa. R. Yoshino, K. M. Young, M. C. Zarnstorff. V. S. Zaveryaev, S. J. Zweben, in Proceedings of the Eleventh International Conference on Plasma Physics and Controlled Nuclear Fusion Resenrch (IAEA, Vienna, 1987), Vol. 1. p. 51. 


\section{FIGURE CAPTIONS}

FIC. 1. a) Growth rate $\gamma$ and b) real frequency $\omega_{i r}$ versus $\eta_{i}$, in units of the electron diamagnetic drift frequency. $\omega_{\text {.ee }}$ for the CIT case. Here. $\eta_{e} / \eta_{i}=0.955$ and the total pressure gradient are kept fixed as $\eta_{i}$ varies.

FIG. 2. a) Growth rate $\gamma$ and b) real frequency $\omega_{r}$ versus $k_{g} \rho_{i} \propto n$, in units of $10^{5} \sec ^{-1}$. for the CIT case.

FIG. 3. Non-Maxwellian equilibrium distribution function $F_{b}$ for the hot neutral beam species versus energy $E$ and dimensionless pitch-angle variable $v_{\|} / v$, for the TFTR case.

FIG. 4. a) Growth rate $\gamma$ and b) real frequency $\dot{c}_{r}$ versus $\eta_{i}$, in units of $10^{5} \mathrm{sec}^{-1}$, for the TFTR case. Here, $\eta_{e}=1.15$ and the total pressure gradient are kept fixed as $\eta_{i}$ varies.

FIG. 5 . Electrostatic potential eigenfunction $\bar{\Phi}(\theta)$ versus $\theta$, the extended poloidal angle (ballooning coordinate along the magnetic field line) for the TFTR case for a) $\eta_{i}=0$ and b) $\eta_{i}=3$.

FIG. 6. a) Growth rate $\gamma$ and b) real frequency $\omega_{\mathrm{r}}$ versus $k_{\theta} \rho_{i} \propto n$, in units of $10^{5} \mathrm{sec}^{-1}$, for the TFTR case.

FIG. 7 . Ratios of quasilinear fluxes for the TFTR case with no beam species versus $\eta_{i}$. Here. $\Gamma$ is the particle flux of electrons and ions, and $Q_{j}$ is the total energy flux of species $j$, including the convective part. Also, $\eta_{e}=1.15$ and the total pressure gradient are kept fixed as iti varies. 

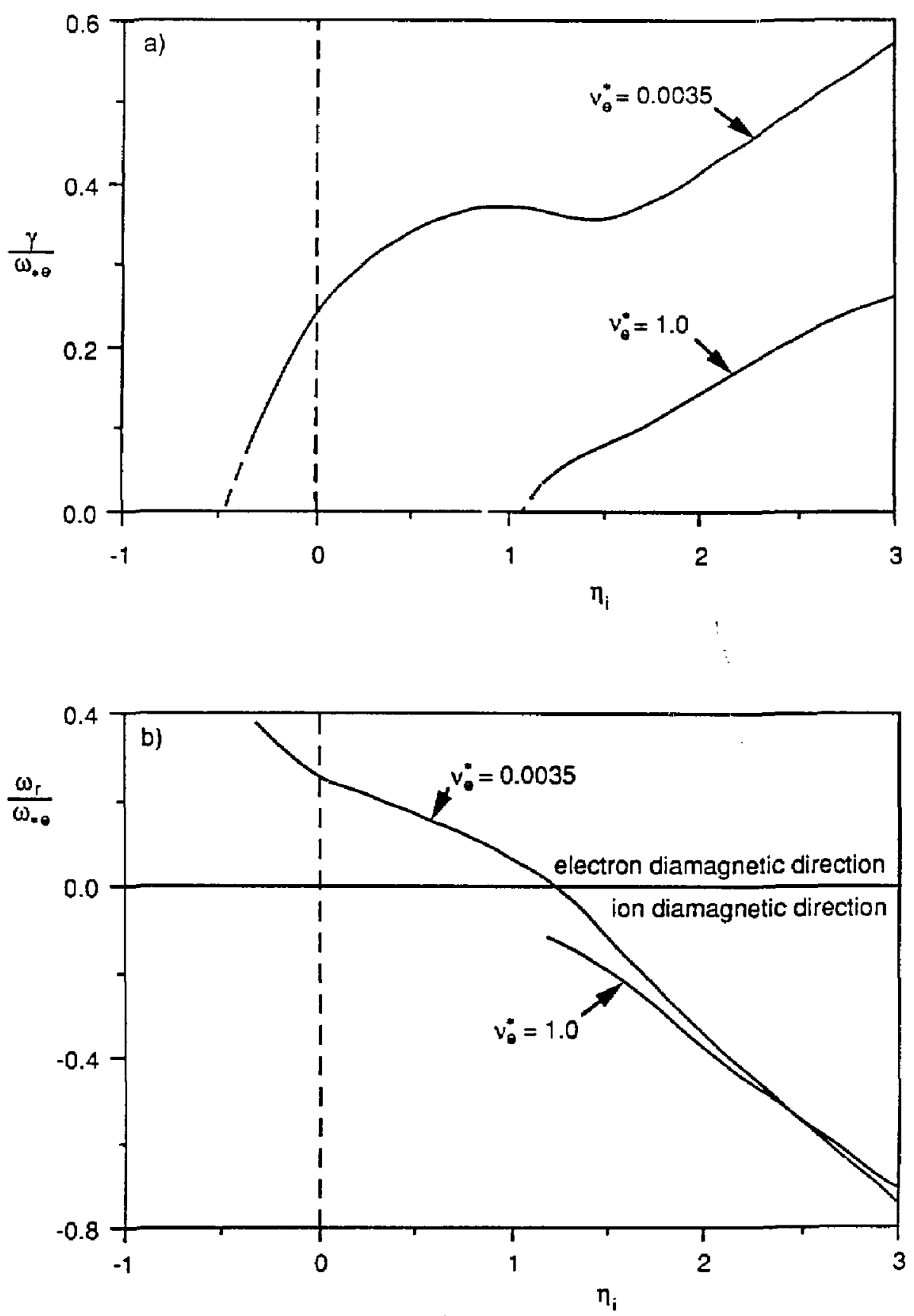

Fig. 1 

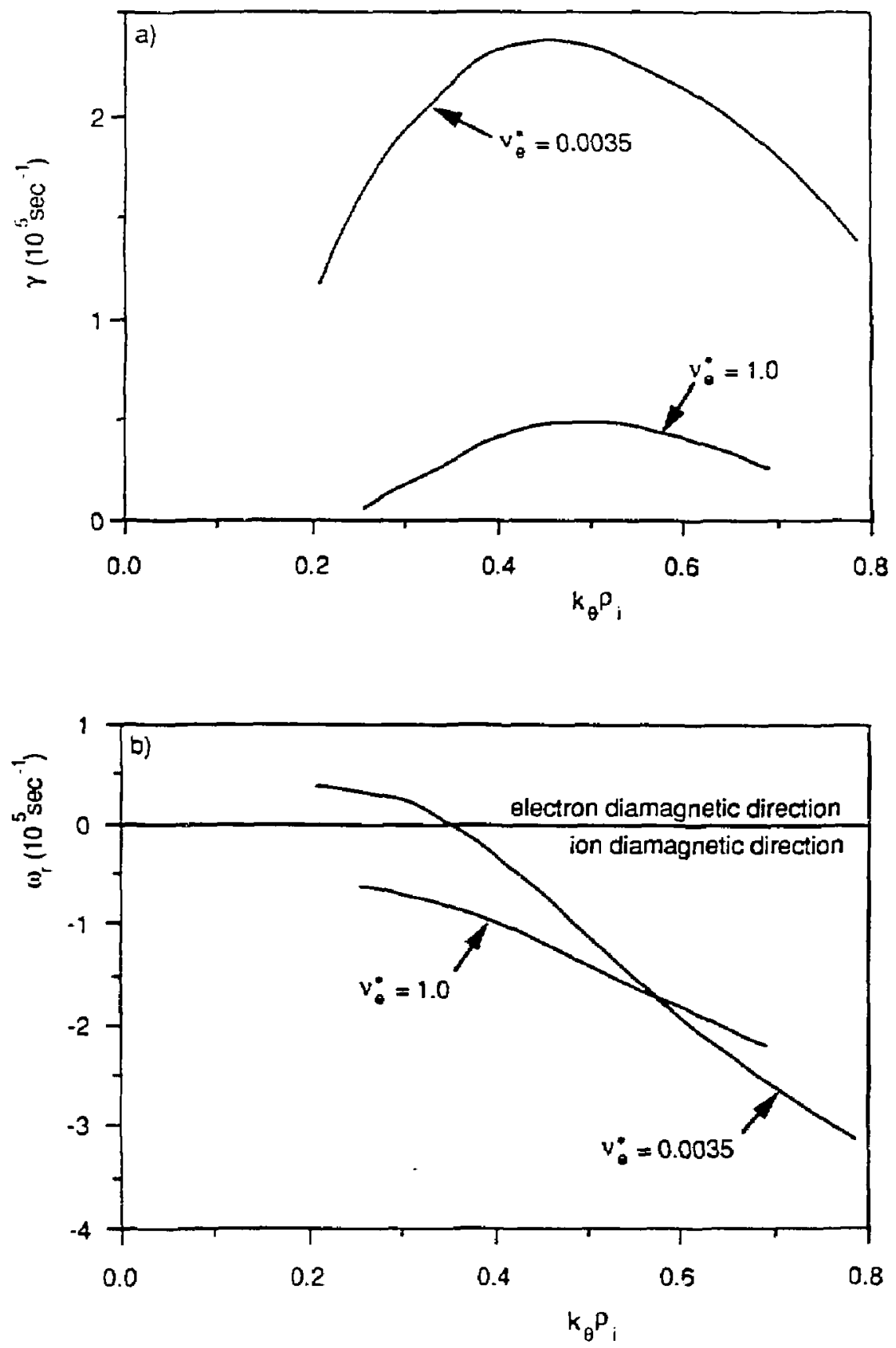

Fig. 2 


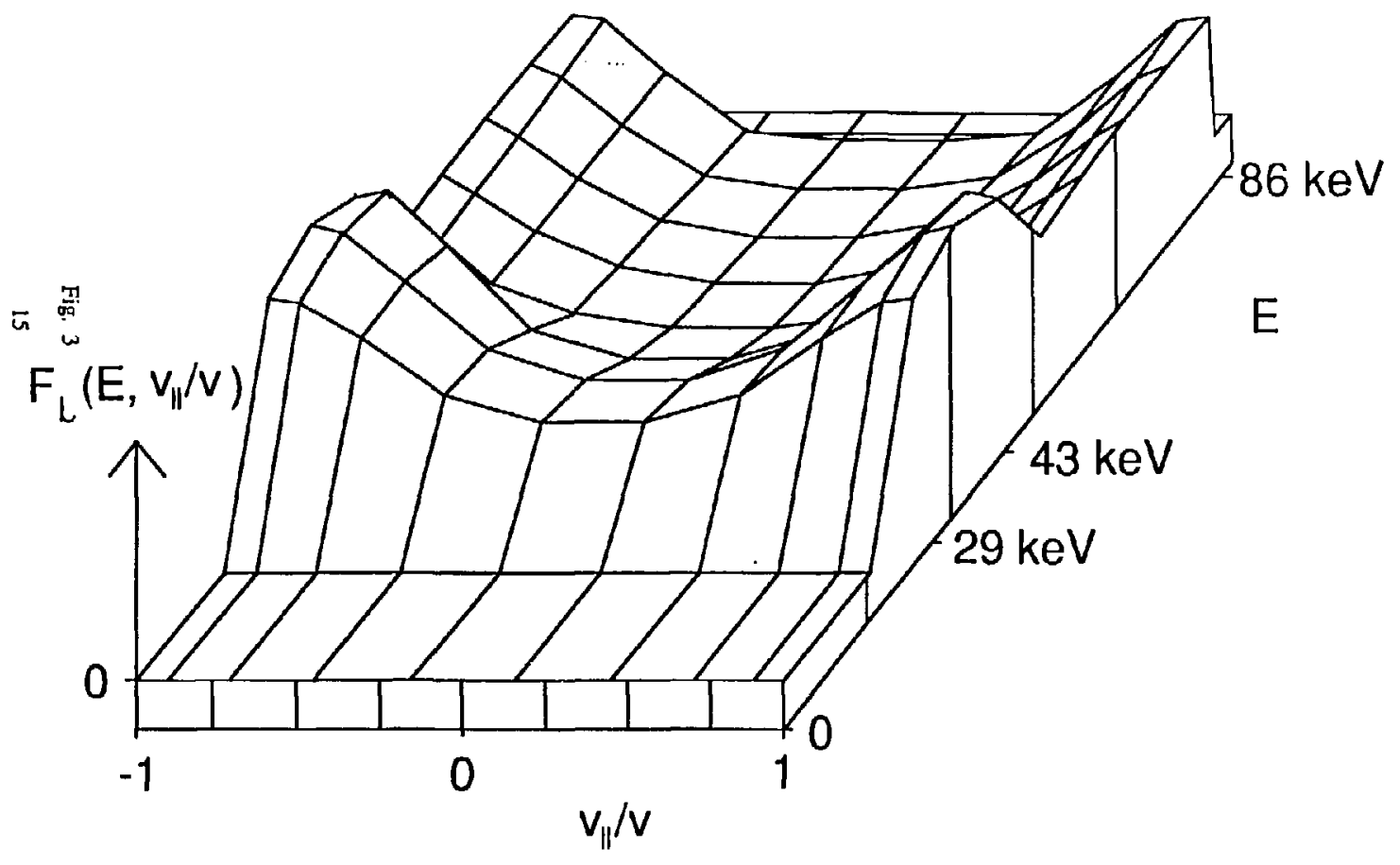



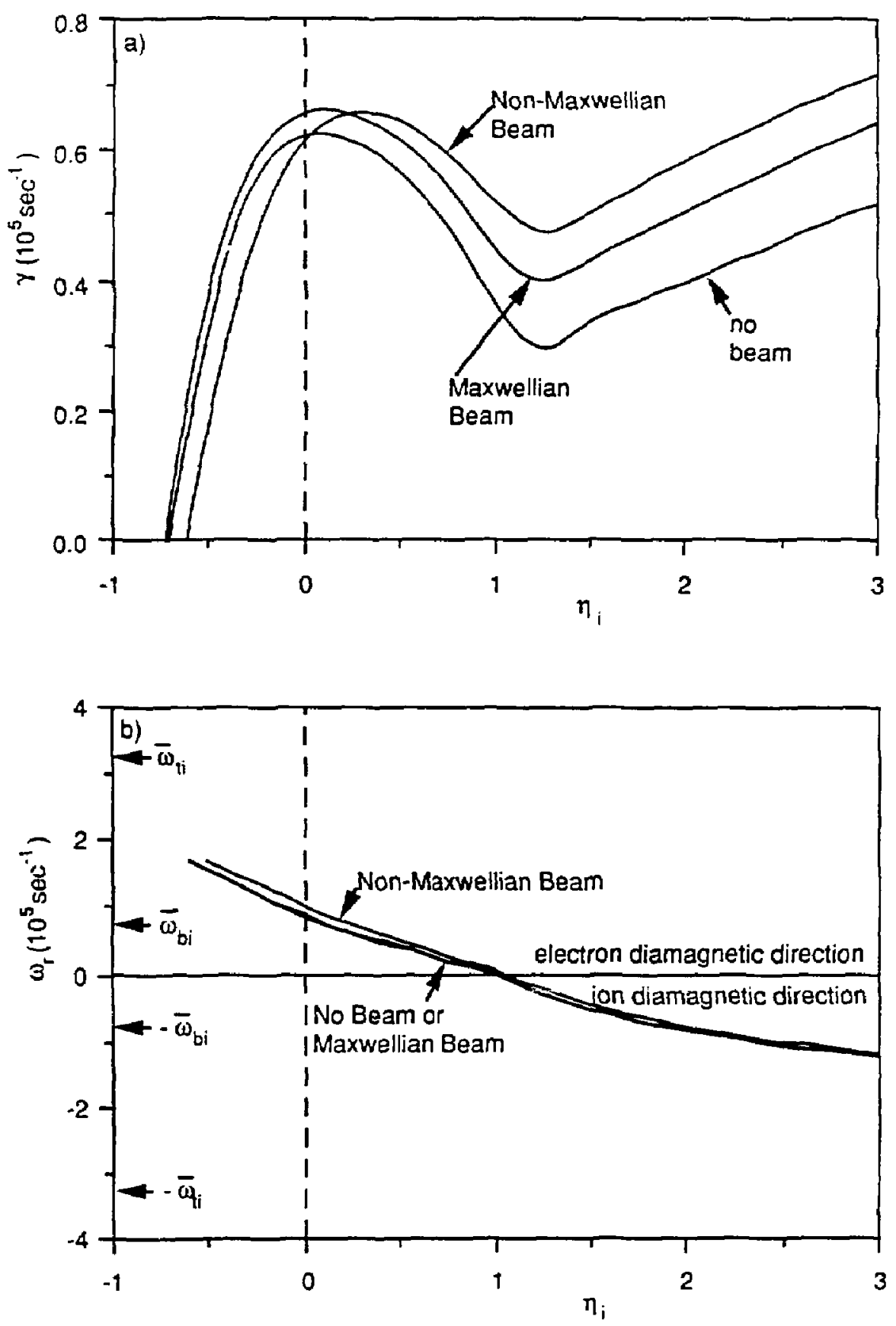

Fig. 4 

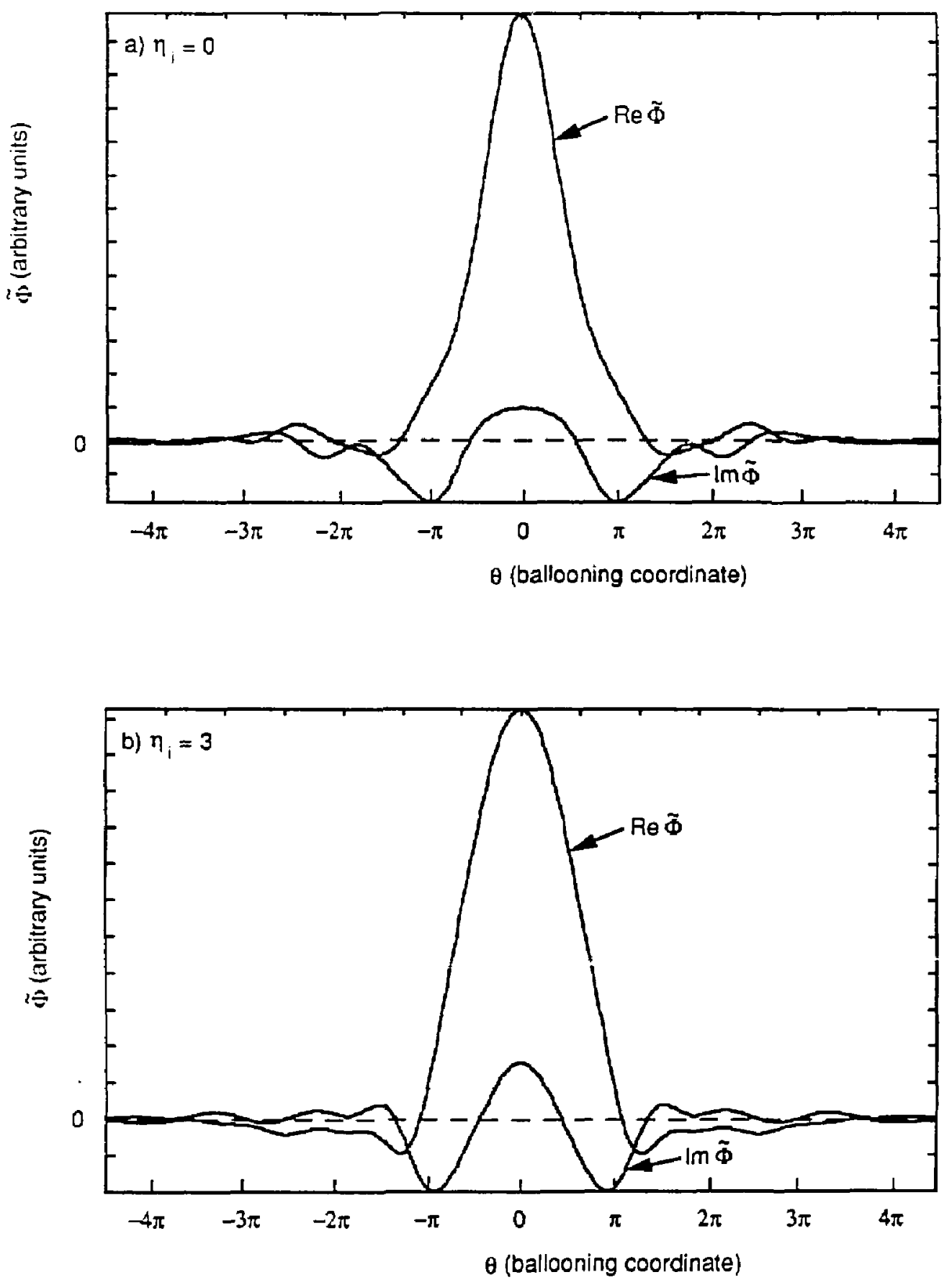

Fig. 5 

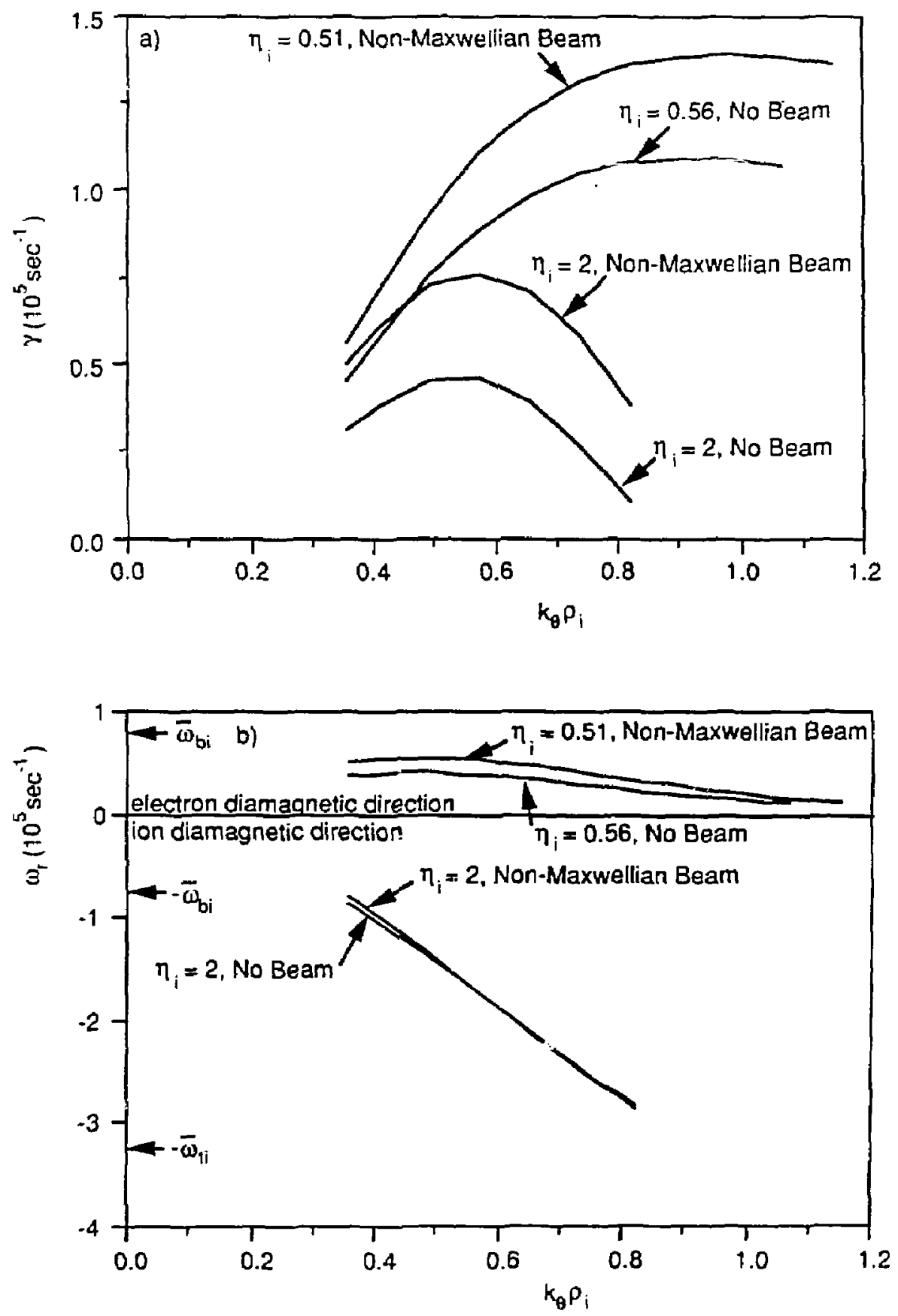

Fig. 6 


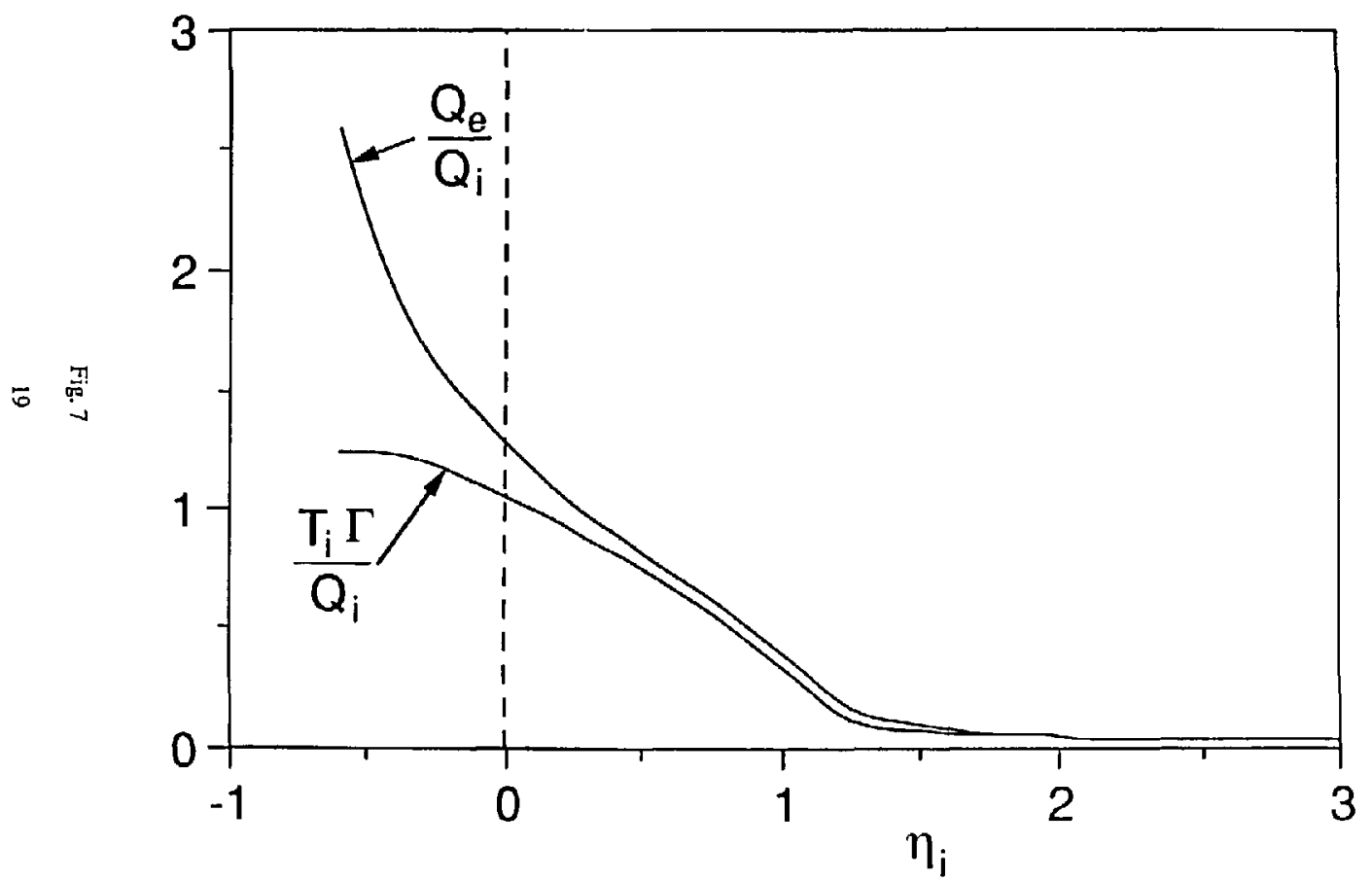


Jr. Frank J. Fooloni, Univ of walongong, atustalia

Prot. H.H. Eronnan, Unir Syaney, Austrealia

plasma Research lao., Austrajion Nat. Univ., AuStRal IA

Prot. I.R. Jones, Flinders Univ.. AUSTaAlia

Prof, F. Cad, Inst Theo Phys, AustRia

Prot. M. Wingler, Instut fur Theoretische Physik, Austria

M. Goossens, Astrononisen lastituut, BELGrum

Ecole Royale Mllitaire, Lab de Phys Plasmas, BELGIUM

Comission-European, Dg-x/I Fusion Prog, BELGium

Prof. R. Goue iqué, Ri jksuniversiteit Gant, BELGium

Dr. P.H. Sakangka, instituto Fisica, ERAz'L

instituto De Pesquisas Espacidsi-IRPE, gRAZIL

Documants Oftice, Atomic Energr of Cangde Limitod, CANADA

Dr. M.P. Bachynski, MPB Tachnologies, Inc., CANADA

Dr. H,M. Skarsgaro, University of Saskatchaman, CANAOA

Dr. H. Garnard, University of Gritist. Columbia, CANADA

Prof. J. Teichmann, Univ. of montreal, CANADA

Prot. S.R. Sremivasan, Univarsity of Calgary, CANADA

Prot. Tudor W. Johnston, IRRS-Enargit. CANADA

Dr. Bolton, Centre canadien dusion megnetique, CANADA

Or. C.R. Jams, Unir. of Albarta, CANhDA

Dr, Feter Lukec, Komenskmo Univ, CZ, at: OV/ it

The Libearion, Culine Leboratory. ENG.

The Librarian, Ruthertord Appleton Labors. , ENGLAND

Mrs. 5.A. Hutehinson, JET Library, ENGLAND

c. Houttet, Lab. de Physique des Milibux lonises, FRANCE

J. Raget, CEN/CAQARAOAE - 85t 506, FRAMCE

45. C. Rinni, Librarian, Univ, of loannina. GAEECE

Or. Ton Mual, Acadeay Btbliograpnic Sar., Motw kong

Prearint Liorary. Hungarien Acedeny of Seiences, HUMGaRY

Or. B. Das Gupta, Sake inst of Nuel. Phys., WOIA

Or. F. Kaw, Institute for Plasma Research, vota

Jr. Prilip Posenau, Israed Inst. of Teen, SAAEL

Liprarian, Int' I Ctr Theo Phys, ITALY

Prof. G. Rostagni, Istituto Gas lonizzati Je: CAR, I IALY

Mis Clelia Do Palo, Assoc EURATOM-ENEA, I IALT

Or. G. Grosso, Istituto di Fisica del Plasma, ITALY

Dr. H. Yameto, Toshibe Res a Dev, Japan
Prof. Kamakami, Atomec Energy Res. Insti*ute, JAPAN

Prot. Kyoj, Nishikawa, Uniy of Hirosnima, JAPAN

Director. Dedt. Large Tomamak Res. JAERl, JAPAN

Prof. Satoshi I ron, Kyushy University, JAPAN

Resuarch into Contar, Nagova Univers,ty, JAPAN

Prol. 5. Tandka, Kyoto University, JAPAN

Liarary, Kroto Universiry, JAPAN

Prot. Hoduruki inoud, University of Tokyo, JAPAN

S. MOR I, JAERI, JAPAN

H. Jeong. Librorian, Kores Advanced Energy Res inst, KORE: Prot, 0.1. Cmoi. The kores Aov, Inst of sci b Tech. KOREs

Prol. g.S. Liloy, University of Waikoto, NEW ZEALAND institute of Plosma Physies. PEOPLE's REPUELIC OF CHINA Librarian, Institute of Fhys., PEOPLE'S REPUBLIE OF CHINA Liorary. Tsing Hua University, PEOPLE'S REPUBLIC OF CHINA 2. Li, Southmest inst. Physies, PEOPLE'S REPUELIC OF CHIMA Prof. J.A.C. Caorol, Inst Suderior Teenico, PORTUGat Dr. Detavian Potrus, al I CUzh University, Romani A Or. Jam co Villiers, Fusion Studios, AEC, SO AFRICA Prof. M,A. Hellberg. University of Matal, SO AFRICA C.I.E,M.A.T. Fusion Div. Library, SPAIN

Or. Lennart Stonflo, Univorsity of UMEA, SHEDEN Liorary, Royas Institure of Teen, SWEDEN Prof. Hans Wilinimson, Chalaers Univ of Tach, SWEDEN Centre Phys des PIasmas, Eeole Polytecn Fed, SWITZERLANO Bibliotheek, Fom-Inst Yoor Plasma-Fysica, THE NETHERLANDS Met in Durgut, Migale East Tectnical Universit;, TURKEY

Dr. D.D. Ryurov, Siberian Acad Sej, USSR

Dr. G.A. Eliseev, Kurchatov institute, USSR

Dr. V.A. Glukhikn, Inst Electrophysical Apoararus, USSA Prot. 0,5. Padichenko, Inst. of Phys. S Tech. USsa Dr. L.M. Koyrizhnykn, Institute of Gen. Physies, USSR Nuclear Res. Establishment, Julien Lto., W. GeRuany Bibligthek, Inst. Fir Plesmaforsenung, W. GEPaAr Dr. K. Schindlar, Ruhr-Universitot Bochum, H. GEPoMANY ASDEX Aasding Aw, c/o Wogner, IPPMax-PI Ionck. W. GEPWANY Librarian, Max-PIanck institut, H. GEFaAky Prof. R.K. jorev, inst of Phys, Yugoslavia 